\title{
Acute tryptophan depletion evokes negative mood in healthy females who have previously experienced concurrent negative mood and tryptophan depletion
}

\author{
Oliver J. Robinson • Barbara J. Sahakian
}

Received: 22 December 2008 / Accepted: 25 March 2009/Published online: 16 April 2009

(C) The Author(s) 2009. This article is published with open access at Springerlink.com

\begin{abstract}
Introduction The majority of individuals who suffer an episode of depression go on to experience recurrences. We have proposed, based upon the observation that reducing serotonin via acute tryptophan depletion (ATD) is more likely to induce negative mood in recovered depressed individuals than never depressed individuals, that this may be because associations form between negative mood and reduced serotonin during an episode of depression (Robinson and Sahakian, Psychol Med 38:315-318, 2008b). Such associations would mean that subsequent reductions in serotonin are more likely to provoke depressed mood and hence trigger an episode of depression.

Methods In this study, we tested this hypothesis by manipulating the mood state of healthy females undergoing ATD (or balanced placebo) on two separate testing sessions. On the first session, subjects received either negative or neutral mood induction, while on the second session all subjects received neutral mood induction.

Results Our findings demonstrate significant ATD-induced negative mood exclusively on the second visit of subjects who received both ATD and negative mood induction procedure on their first visit.
\end{abstract}

O. J. Robinson $(\bowtie) \cdot$ B. J. Sahakian

Department of Psychiatry and Behavioural and Clinical

Neuroscience Institute, University of Cambridge,

Cambridge, Addenbrooke's Hospital,

P. O. Box 189, Level E4, Hills Road,

Cambridge CB2 2QQ, UK

e-mail: oliver.j.robinson@googlemail.com

O. J. Robinson

Section on Neuroimaging in Mood and Anxiety Disorders, National Institute of Mental Health, National Institutes of Health, Bethesda, MD, USA
Discussion These findings may be explained by the formation of an association between the negative mood and reduced serotonin states during the first visit. As such, these findings provide preliminary support for the associative hypothesis of recurrence in depression.

Conclusion Such associations might therefore explain the discrepancy between the effects of ATD in recovered- and never-depressed individuals and may, in turn, explain why an episode of depression increases the risk of subsequent episodes.

Keywords Serotonin $\cdot$ Mood $\cdot$ Females $\cdot$ Recurrence . Depression $\cdot$ Associative learning

\section{Introduction}

Depressive disorders are amongst the leading causes of disability and mortality worldwide and account for more years lived with disease than any other illness (Beddington et al. 2008; Murray and Lopez 1996). Furthermore, the majority of depressed individuals relapse (Mueller et al. 1999), and with each successive episode, the rate of subsequent recurrence increases (Kessing et al. 2004) such that life for most sufferers becomes a chronic cycle of illness and recovery.

The monoamine serotonin (5-HT) is thought to play a role in major depression (Owens and Nemeroff 1994, but see Lacasse and Leo 2005 for an alternative view). Specifically, patients with depression show reduced serotonin levels (Cowen et al. 1989; Placidi et al. 2001), abnormal serotonin receptor function (Drevets et al. 1999; Ellis and Salmond 1994) and abnormal serotonin transporter function (Caspi et al. 2003; Heils et al. 1996; Lesch et al. 1996). Moreover, elevation of serotonin via selective 
serotenergic reuptake inhibitors can reduce the symptoms of depression (Harmer 2008).

One way to manipulate serotonin in healthy individuals is via the dietary manipulation of the serotonin precursor tryptophan (acute tryptophan depletion; ATD). This manipulation is thought to significantly reduce central 5-HT levels (Ardis et al. 2009; Reilly et al. 1997) and can provoke some of the cognitive effects seen in depressed individuals in healthy individuals (e.g. Evers et al. 2006; Murphy et al. 2002; Sambeth et al. 2007). However, ATD has no reliable effects upon the mood state of healthy individuals (Robinson and Sahakian 2009; Ruhe et al. 2007). In individuals who have recovered from depression, on the other hand, ATD can induce significant negative mood (Delgado et al. 1990; Smith et al. 1997), particularly in those who were successfully treated with SSRIs (and therefore presumably had reduced 5-HT) during their first episode (Booij et al. 2003; Van der Does 2001). An important unresolved question, therefore, is why a discrepancy exists between the effects of ATD on mood state in never- and recovered-depressed individuals.

To explain this phenomenon, we have previously proposed a hypothetical neurocognitive mechanism by which mood state and reduced serotonin may become linked during an episode of depression (Robinson and Sahakian 2008b). The central tenet of this hypothesis is that associative learning (Dickinson 1981) causes a link to be formed between the neural substrates implicated in negative mood and the neural substrates implicated in a reduced serotonin state during their depression-linked co-occurrence. Such an association would mean that re-evocation of one state would trigger the other. In other words, a permanent association between negative mood and a low serotonin in depressed individuals would result in negative mood following an ATD-induced low serotonin state. Individuals who have never suffered from depression, on the other hand, are not likely to have previously experienced concurrent reduced serotonin and negative mood, will not have such an association and will not therefore experience ATD evoked negative mood. The term 'kindling' has previously been used to describe the changes that occur during an episode of depression, which promote the onset of future episodes (Kendler et al. 2001; Post and Weiss 1998; Segal et al. 1996). A link between low serotonin and negative mood may therefore underlie such a kindling effect.

In order to test this hypothesis, we attempted to artificially associate negative mood with a reduced a serotonin state in healthy individuals. Mood state was manipulated via an established mood induction procedure (MIP; Robinson et al. 2009; Robinson and Sahakian 2009) and serotonin was manipulated via ATD. Four separate groups were tested on two occasions separated by at least a week. In the main group of interest, subjects received ATD and negative MIP on their first visit but ATD and neutral MIP on their second visit. Another group received ATD on both visits but neutral MIP on both the first and second visit. Two matched control groups received either neutral or negative MIP on their first visit but received a balanced amino-acid drink instead of ATD on both visits. Both control groups also received neutral MIP on their second visit. If our hypothesis is correct, then ATD will have no effect upon mood on the first visit (in all groups) but evoke negative mood on the second visit of the group who received both ATD and negative MIP on their first visit.

This study therefore tested the hypothesis that associations can form between reduced serotonin state and negative mood.

\section{Methods}

Procedures were approved by the Cambridge Research Ethical Committee (06/Q0108/160) and were in accord with the Helsinki Declaration of 1975. Depression is more common in females than males (Kendler et al. 2004), and previous research has demonstrated that ATD has increased effects in females relative to males (Ellenbogen et al. 1996; Robinson et al. 2009; Sambeth et al. 2007) so recruitment was restricted to females. Forty-two subjects were recruited. One subject failed to complete either testing session. The remaining 41 subjects were then divided into four groups: (1) ATD subjects who underwent neutral MIP on visit 1 $(N=11),(2)$ ATD subjects who underwent negative MIP on visit $1(N=10)$, (3) BAL subjects who underwent neutral MIP on visit $1(N=10)$, (4) BAL subjects who underwent negative MIP on visit $1(N=10)$. All subjects received neutral MIP on visit 2. Thirty-eight subjects completed a second session (group $1 N=10$; group 2, $N=8$; group 3 $N=10$; group $4 N=10$; Table 1). All subjects were screened for psychiatric and neurological disorders, gave written informed consent and were compensated for participation. Exclusion criteria were cardiac, hepatic, renal, pulmonary, neurological, psychiatric or gastrointestinal disorders, drug use and personal or family history of any depressive disorder. The mean age of subjects was [years] $28(\mathrm{SD}=6)$. Subjects were tested on two sessions, separated by at least

Table 1 Group description

\begin{tabular}{lllll}
\hline Group & Visit 1 & & Visit 2 \\
\hline 1 & ATD & NEUT MIP & ATD & NEUT MIP \\
2 & ATD & NEG MIP & ATD & NEUT MIP \\
3 & BAL & NEUT MIP & BAL & NEUT MIP \\
4 & BAL & NEG MIP & BAL & NEUT MIP \\
\hline
\end{tabular}


1 week. They were instructed to abstain from alcohol, caffeine and food from midnight prior to each session.

Protocol

Subjects arrived at the research centre between 08:30 and 10:30 and consumed the amino-acid mixture. At $T_{0}$, a blood sample was taken, and a nutritionally balanced (BAL) or a tryptophan free (ATD) amino-acid drink was ingested. Following this, they were allowed to consume water and were given a low protein snack (an apple) for lunch. After a resting period of approximately $5 \mathrm{~h}$ to ensure stable and low tryptophan levels (Carpenter et al. 1998), a second blood sample was taken $\left(T_{1}\right)$, and the mood induction procedure was completed.

\section{Amino-acid mixtures}

Amino-acid mixtures (prepared by SHS international; Liverpool, UK) were identical to previous research (Cools et al. 2007; Robinson et al. 2009; Robinson and Sahakian 2009; Roiser et al. 2006): L-alanine, 2.9 g; L-arginine, 2.6 g; L-cystine, $1.4 \mathrm{~g}$; glycine, $1.7 \mathrm{~g}$; L-histidine, $1.7 \mathrm{~g}$; Lisoleucine, $4.2 \mathrm{~g}$; L-leucine, $7.1 \mathrm{~g}$; L-lysine, $4.7 \mathrm{~g}$; Lmethionine, $1.6 \mathrm{~g}$; L-proline, $6.4 \mathrm{~g}$; L-phenylalanine, $3.0 \mathrm{~g}$; L-serine, $3.6 \mathrm{~g}$; L-threonine, $3.4 \mathrm{~g}$; L-tyrosine, $3.6 \mathrm{~g}$; Lvaline, $4.7 \mathrm{~g}$; L-tryptophan, $2.1 \mathrm{~g}$-total BAL, 54.7/TRP, $52.6 \mathrm{~g}$. The drinks were prepared by stirring the mixture into approximately $200 \mathrm{ml}$ tap water with either lemon-lime or grapefruit flavouring. Subjects reported no side effects apart from transient nausea following ingestion of the drink.

Blood (venous) samples $(10 \mathrm{ml})$ were taken immediately before ingestion of the amino-acid drink $\left(T_{0}\right)$ and approximately $5 \mathrm{~h}$ after administration $\left(T_{1}\right)$ to determine the crucial $\mathrm{TRP} /$ sum of the long neutral amino acids ( $\Sigma \mathrm{LNAA}$ ) ratio.

Mood induction procedure

The MIP has been comprehensively described elsewhere (Robinson et al. 2009; Robinson and Sahakian 2009). Subjects were asked to relate negative or neutral Velten sentences to situations in their own lives whilst listening to mood-congruent music. It was programmed in Microsoft Visual Basic 6 (Microsoft Corporation, Redmond, WA, USA) and presented on a Paceblade tablet computer (11-in. monitor). A set of visual analogue scales (VAS) was administered at $T_{0}$ (admission), $T_{1}$ (5 h later pre-MIP) and $T_{2}$ (post-MIP) to determine self-reported mood.

\section{Results}

\section{Amino-acid mixtures}

Incomplete amino-acid data (Table 2) were available for ten participants due to blood extraction problems, but it should be noted that the same amino-acid mixture (made by the same manufacturer) was successfully used in three previous studies (Cools et al. 2008; Robinson et al. 2009; Robinson and Sahakian 2009). A repeated-measures ANOVA revealed a significant two-way drink $\times$ time interaction for the critical TRP $/ \Sigma L N A A$ ratio (treatment $\times$ time: $F_{1,29}=59, P<0.001$ ).

Simple effects analysis revealed that the significant drink $\times$ time interaction was due to a $92 \%$ decrease in the TRP/ $\Sigma$ LNAA ratio between $T_{0}$ and $T_{1}$ following ATD (significant effect of time: $F_{1,29}=44.7, P<0.001$ ) and a $64 \%$ increase in the TRP/ $\Sigma$ LNAA ratio between $T_{0}$ and $T_{1}$ following BAL $\left(F_{1,29}=18.5, P<0.001\right)$.

A similar pattern was seen in the TRP levels on their own (treatment $\times$ time: $F_{1,29}=56, P<0.001$; significant effect of time under ATD: $F_{1,29}=6.9, P=0.013$ and BAL: $\left.F_{1,29}=61, P<0.000\right)$.

\section{Mood state}

Incomplete VAS scales were available for the first visit of four subjects (one per group) and for the second visit of two subjects (one in group 1 , one in group 4).

\section{Visit 1}

There were no treatment by time $\left(F_{1,33}=0.046, P=0.83\right)$, time by $\operatorname{MIP}\left(F_{1,33}=0.13, P=0.73\right)$ or treatment by time by MIP interactions $\left(F_{1,33}=0.50, P=0.48\right)$ between $T_{0}$ and $T_{1}$ on the Sad VAS subscale. The same absence of an effect was seen on the happy VAS (no effect of treatment $\times$ time, $F_{1,33}=0.68, P=0.42$; time $\times$ MIP, $F_{1,33}=1.6, P=0.22$; or treatment $\times$ time $\times$ MIP interaction $F_{1,33}=0.51, P=0.48$ ). This indicates that the drink itself did not change subjects' mood and that this did not differ between groups.

Table 2 Biochemical measures

\begin{tabular}{|c|c|c|c|c|c|c|c|c|c|}
\hline \multirow{3}{*}{ Bioch } & & \multicolumn{4}{|l|}{ BAL } & \multicolumn{4}{|l|}{ ATD } \\
\hline & & $T_{1}$ & & $T_{2}$ & & $T_{1}$ & & $T_{2}$ & \\
\hline & TRP (nmol/ml) & 34 & (3.3) & 108 & (10) & 34 & $(3.2)$ & 10 & $(9.8)$ \\
\hline Values represent mean (standard & TRP/ $\Sigma$ LNAA & 0.11 & $(0.01)$ & 0.18 & $(0.02)$ & 0.12 & $(0.01)$ & 0.01 & $(0.02)$ \\
\hline
\end{tabular}




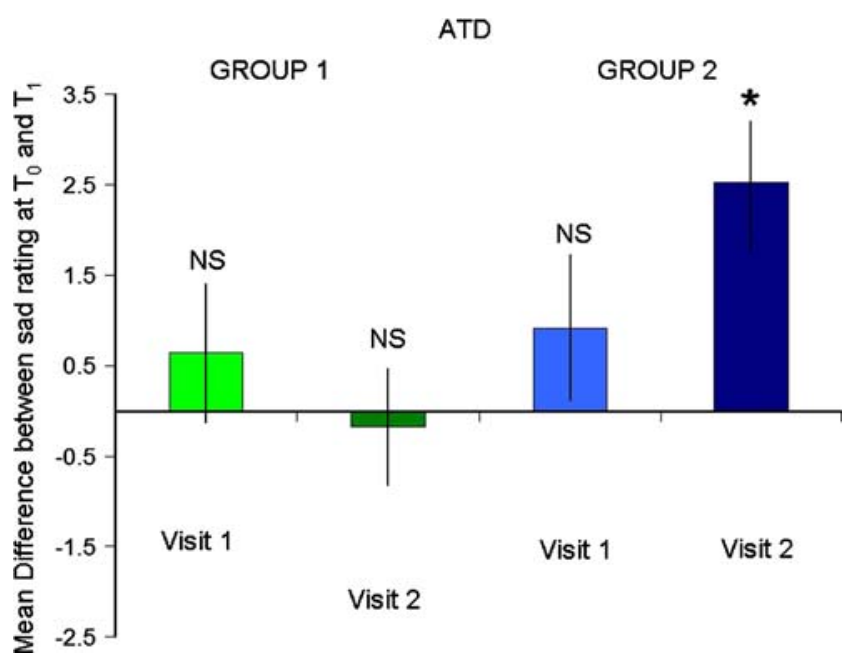

Fig. 1 Mean difference in the self-report visual analogue scale 'How sad are you?' between $T_{0}$ and $T_{1}$ in subjects undergoing ATD. ATDinduced significant negative mood on visit 2 of those subjects who received ATD and negative MIP during visit $1\left({ }^{*} P=0.001, N S\right.$ not significant)

However, there was an effect of time between $T_{1}$ and $T_{2}$ before and after the MIP on the sad VAS $\left(F_{1,34}=9.7, P=\right.$ $0.004)$ and although there was no time by $\operatorname{MIP}\left(F_{1,34}=2.2\right.$, $P=0.15)$ interaction or time by MIP by treatment interaction $\left(F_{1,34}=0.076, P=0.79\right)$, when stratified by group, there was a significant increase in sad ratings in the negative (main effect of time; $F_{1,34}=9.9, P=0.003$ ) but not neutral mood group (no effect of time; $F_{1,34}=1.44, P=0.24$ ). There was also an effect of time $\left(F_{1,34}=5.3, P=0.027\right)$ and a nonsignificant trend towards a time by mood interaction on the happy VAS $\left(F_{1,33}=3.4, P=0.074\right)$ which was again, when stratified by group, driven by a significant reduction in happy ratings (main effect of time; $F_{1,33}=8.2, P=0.007$ ) in the negative but not neutral MIP (no effect of time; $F_{1,33}=$ $0.11, P=0.74$ ) group. Thus, the negative MIP increased sad and decreased happy ratings, whereas the neutral MIP had no effect on either rating. Thus, although there was no significant main effect, there was a non-significant trend in the 'happy' ratings, and the simple effects were significant in both happy and 'sad' ratings. As such, we argue thatconsistent with previous studies utilising the same technique (Robinson 2009; Robinson et al. 2009; Robinson and Sahakian 2009) - the MIP was successful. The alternative assumption (that the MIP was unsuccessful) cannot account for the significant findings on the second visit. The lack of a main effect may be due to reduced statistical power resulting from a non-optimal sample size.

\section{Visit 2}

There was a significant interaction between time, treatment and MIP between $T_{0}$ and $T_{1}$ on the sad VAS $\left(F_{1,32}=8.0, P=\right.$
0.008). This was driven by a significant lowering of mood in the subjects in group 2 (who underwent both negative MIP and ATD on the first visit: main effect of time $F_{1,32}=$ $14, P=0.001$ ) but no change in the moods of groups 1 (no effect of time $F_{1,32}=0.077, P=0.78$ ), 3 (no effect of time $F_{1,32}=0.11, P=0.74$ ) or 4 (no effect of time $F_{1,32}=1.3, P=$ 0.25 ). There was no such interaction on the happy VAS (no time $\times$ treatment $\times$ mood interaction: $F_{1,32}=0.034, P=$ 0.85). Thus, ATD evoked negative mood but only in those subjects who received both negative MIP and ATD on their first visit (Figs. 1 and 2).

There was also an interaction between time, treatment and MIP before $\left(T_{1}\right)$ and after $\left(T_{2}\right)$ the neutral MIP on the sad VAS $\left(F_{1,32}=5.6, P=0.024\right)$. This was due to a significant reduction in sad ratings following the MIP in group 2 (main effect of time $F_{1,32}=9.8, P=0.004$ ) but no change in the moods of groups 1 (no effect of time $F_{1,32}=$ 1.6, $P=0.22$ ), 3 (no effect of time $F_{1,32}=0.37, P=0.55$ ) or 4 (no effect of time $F_{1,32}=0.6, P=0.46$ ). There was no such interaction on the happy VAS (no time $\times$ treatment $\times$ mood interaction: $\left.F_{1,32},<0.000, P=0.98\right)$. Thus, the neutral MIP actually served to neutralise the negative mood state induced by ATD in group 2 .

It should be noted that the effect of interest is only revealed when time is included as a within subjects factor. There is no significant difference between the sad ratings of each group at each time point (Table 3). In other words, there is a significant within- but not between-subjects change in mood state. This indicates that although a combination of ATD and mood induction on the first visit caused a significant change in mood state on a second visit, this change nevertheless remains within the boundaries of 'normal' sad mood ratings.

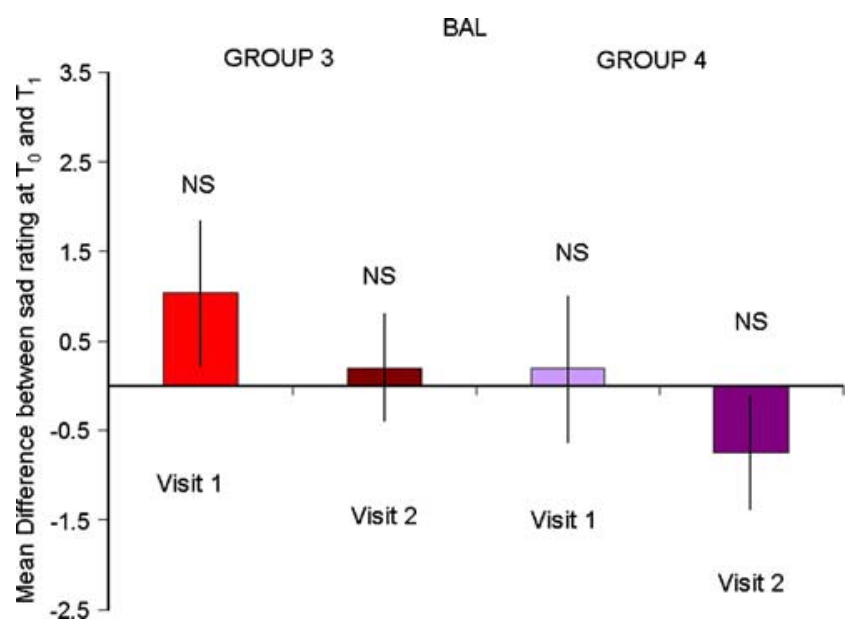

Fig. 2 Mean difference in the self-report visual analogue scale 'How sad are you?' between $T_{0}$ and $T_{1}$ in subjects undergoing BAL. No changes in mood were seen (NS not significant) 
Table 3 Visual analogue ratings

\begin{tabular}{|c|c|c|c|c|c|c|c|}
\hline \multicolumn{2}{|c|}{ Group } & \multicolumn{2}{|l|}{$T_{0}$} & \multicolumn{2}{|l|}{$T_{1}$} & \multicolumn{2}{|l|}{$T_{2}$} \\
\hline \multicolumn{8}{|c|}{ Visit 1} \\
\hline 1 & $(N=10)$ & 1.32 & $(0.71)$ & 1.52 & $(0.62)$ & 2.06 & $(0.77)$ \\
\hline 2 & $(N=9)$ & 0.41 & $(0.82)$ & 0.94 & $(0.70)$ & 3.43 & $(0.91)$ \\
\hline 3 & $(N=9)$ & 1.53 & $(0.72)$ & 2.57 & $(0.62)$ & 3.2 & $(0.80)$ \\
\hline \multirow[t]{2}{*}{4} & $(N=9)$ & 2.67 & $(0.71)$ & 2.86 & $(0.62)$ & 4.29 & $(0.77)$ \\
\hline & ANOVA & \multicolumn{2}{|c|}{$F_{3,33}=1.5, P=0.24$} & \multicolumn{2}{|c|}{$F_{3,34}=0.6, P=0.62$} & \multicolumn{2}{|c|}{$F_{3,35}=0.83, P=0.49$} \\
\hline \multicolumn{8}{|c|}{ Visit 2} \\
\hline 1 & $(N=9)$ & 2.21 & $(0.74)$ & 2.03 & $(0.74)$ & 2.66 & $(0.76)$ \\
\hline 2 & $(N=8)$ & 0.64 & $(0.87)$ & 2.9 & $(0.87)$ & 1.27 & $(0.89)$ \\
\hline 3 & $(N=10)$ & 2.96 & $(0.76)$ & 2.93 & $(0.77)$ & 3.6 & $(0.79)$ \\
\hline \multirow[t]{2}{*}{4} & $(N=9)$ & 2.42 & $(0.74)$ & 1.68 & $(0.74)$ & 2.06 & $(0.76)$ \\
\hline & ANOVA & \multicolumn{2}{|c|}{$F_{3,33}=1.7, P=0.19$} & \multicolumn{2}{|c|}{$F_{3,32}=1.1, P=0.36$} & \multicolumn{2}{|c|}{$F_{3,32}=1.09, P=0.37$} \\
\hline
\end{tabular}

\section{Discussion}

Tryptophan depletion had no effect upon the mood state of healthy females on their first visit. However, those who received negative mood induction following tryptophan depletion during their first visit experienced a significant lowering of mood following tryptophan depletion on their second visit. This effect was not seen in those who experienced a neutral mood induction and tryptophan depletion on their first visit or in those who received a balanced placebo and negative mood induction on their first visit. This finding therefore provides preliminary experimental data to support the associative hypothesis of recurrence in depression (Robinson and Sahakian 2008b) and may therefore explain the discrepancies between the effects of tryptophan depletion in never- and recovereddepressed individuals (Booij et al. 2002).

The first important finding, therefore, is that there was no significant change in mood between $T_{0}$ and $T_{1}$ on the first visit of all four groups. This supports the hypothesis that tryptophan depletion does not, in itself, cause negative mood. Although this is inconsistent with early reports (Young et al. 1986, 1985), more recent studies have failed to replicate these findings (Booij et al. 2003, 2002), and it is now thought that any link between 5-HT and mood is likely to be indirect (Robinson and Sahakian 2009; Ruhe et al. 2007). Moreover, the present data demonstrate that ATD does not necessarily induce negative mood in healthy females, despite the suggestion that female gender might be a risk factor for mood response to ATD (Booij et al. 2002). Thus, this finding supports the hypothesis that ATD does not induce negative mood state in healthy individuals who have never suffered from (and are not predisposed to) depression.

The observation that tryptophan depletion did induce negative mood on the second visit of those who received both negative mood and ATD on their first visit then supports the associative hypothesis of recurrence in depression (Robinson and Sahakian 2008b). Negative mood and reduced serotonin frequently co-occur in depression (APA 2000; Owens and Nemeroff 1994), and ATD provokes significant negative mood in subjects who have previously suffered from depression (Booij et al. 2002). The present findings therefore suggest that ATD may provoke negative mood in (at least some) recovered depressed individuals because both negative mood and reduced serotonin co-occurred during their first episode of depression.

An important question, therefore, is why previous cooccurrence of negative mood and low serotonin would cause ATD to become linked with negative mood. A number of theories which are relevant to this phenomenon have been highlighted (Robinson and Sahakian 2008b). The most important of these is associative learning theory, which describes how two events (in this case, negative mood and reduced serotonin) can become linked by occurring at the same time (Dickinson 1981). Future occurrence of one event then re-evokes the other. Such learning is thought to be underpinned at the neural level by Hebbian learning (Paulsen and Sejnowski 2000) in which 'cells that fire together, wire together'. If both the negative mood and reduced serotonin states evoke dissociable patterns of neural activity, then these patterns of neural activity may 'wire together' when they co-occur during an episode of depression (or, indeed, in the artificial situation in the present study). In particular, mood states are associated with activity in prefrontal cortical regions (Garrett and Maddock 2006; Habel et al. 2005; Mayberg et al. 1999; Mitchell and Phillips 2007; Taylor Tavares et al. 2008), whereas serotonin influences a diverse range of cortical and subcortical regions (Cools et al. 2005; Harmer 2008; Roiser et al. 2007; van der Veen et al. 2007). Thus, the neurons responsible for the prefrontal activations associated with negative mood may wire together with the distinct cortico-subcortical pattern 
associated with the reduced serotonin state. This is redolent of the 'as-if body' loop outlined by Damasio (2000), which postulates that the neural substrates associated with moods can be independently evoked in the absence of the somatic changes, which may have originally triggered the state.

It should be noted that the restriction of this finding to group 2 indicates that the negative mood state is specifically associated with the reduced 5-HT state. The absence of the effect in group 4 indicates that negative mood cannot be associated with a more general state such as altered aminoacid levels or discomfort caused by the drink and/or the long waiting period. In other words, this effect is not driven by a general state-dependent recall of mood. The reduced 5-HT may therefore provoke increased activation in specific brain regions (e.g. the striatum Roiser et al. 2007), which may then became associated with the neural substrates specific to the negative mood state (e.g. regions of the PFC (Gray et al. 2002; Robinson and Sahakian 2009)). However, this associative hypothesis is clearly speculative, and the next step will be to use functional neuroimaging to examine the neural substrates underlying these preliminary behavioural observations.

This study may also have important implications for our understanding of relapse in depression. Following a first episode, subsequent episodes become increasingly likely (Kendler et al. 2001), and these episodes become increasingly debilitating (Bouhuys and Sam 2000; Fossati et al. 2004; Nandrino et al. 2004; Nandrino et al. 2002; Sher et al. 2004; Thase et al. 1995) and increasingly easy to trigger (Lewinsohn et al. 1999). The concept of 'kindling' has been proposed to explain this pattern (Kendler et al. 2001; Post and Weiss 1998; Segal et al. 1996). In particular, it has been suggested that permanent changes might occur during a first episode of depression, which may make subsequent episodes more likely. The present data highlight the possibility that a permanent neural association between reduced serotonin and negative mood, formed during an episode of depression, may underlie this kindling effect. Such an association may mean that subsequent fluctuations in serotonin levels are more likely to trigger depressed mood and hence instigate a 'downwards spiral' into depression. Such associations could also be partially responsible for the cognitive impairment which can appear in remission in recovered depressed individuals (Paradiso et al. 1997).

These findings therefore highlight the importance of treating not only the initial symptoms of depression but also any underlying kindling. Specifically, it may be important to attempt to break these proposed associations after an episode of depression has been successfully treated. Associative learning theory suggests that new associations are formed over the top of old associations rather than old associations being 'un-learned' (Bouton 2002). Thus, one potential method of treating associations might be to attempt to associate reduced serotonin with a positive mood state in recovered depressed individuals. The observation that the neutral mood induction improved the ATD induced negative mood in the present study indicates that this may be possible. Recovered depressed individuals could therefore be tryptophan-depleted and then subjected to positive MIP (Robinson et al. 2009; Robinson and Sahakian 2008a; Robinson and Sahakian 2009; Roiser et al. 2008) or behavioural therapy to elevate mood. If the associative hypothesis is correct, then an association may form between the low serotonin state and the positive mood state. As such, future fluctuations in 5-HT level should evoke positive rather than negative mood and thereby act as a buffer against the onset of depression. Nevertheless, this hypothesis is clearly speculative and requires further research.

It should be noted that whilst this hypothesis explains a number of previously observed discrepancies, it does not cover all eventualities. For instance, ATD has actually been shown to induce negative mood in healthy individuals who are at risk of depression (Booij et al. 2003; Booij et al. 2002; Neumeister et al. 2002; Ruhe et al. 2007). As such individuals have never suffered from an episode of depression the proposed hypothesis cannot explain their responses. It could be argued that their susceptibility to depression is provoked by the pre-existence of the proposed 5-HT and mood associations or that their susceptibility means that they are likely to have experienced sub-clinical episodes of negative mood and reduced serotonin, but these arguments are clearly speculative. Similarly, it should be noted that depression is a multi-faceted disorder and that not all sufferers experience reduced serotonin. Prior exposure to SSRIs has been shown to be a predictor of mood response following ATD (Booij et al. 2002), so it is plausible that ATD-induced negative mood is only found in subjects whose depression was associated with reduced 5-HT, but this is also clearly speculative. It should therefore be emphasised that the proposed hypothesis is only really applicable to individuals who have experienced an episode of depression and who experienced reduced 5-HT during that episode.

As a further caveat, it should be noted that self report is an imperfect method of measuring mood state because it can be heavily reliant upon demand characteristics (Orne 1969). This is particularly likely to be an issue with selfreported mood following mood induction as the desired mood state is likely to be fairly obvious to the volunteer. However, it should be noted that the effect of interest in the present findings was on the second visit prior to the MIP. Thus, at $T_{1}$ on the second visit, the experiences of all groups were closely matched. An alternative demand characteristic may be that those who experienced negative 
MIP on the first visit would expect a negative MIP on the second visit. They may therefore report anticipatory negative mood just prior to the MIP. However, if this were the case, then self-reported negative mood would also be expected in the BAL group who experienced negative MIP on their first visit. The restriction of the finding to the one group suggests that the effect is indeed specific to those who experienced both negative MIP and ATD on the first visit. It should also be noted that one-way ANOVAs revealed no significant differences between the ratings of each group at each time point (see Table 3). This means that none of the groups had abnormally low or high baseline mood ratings. As such, the ratings stayed within normal mood state, and significant effects were driven by significant within-subject changes in mood state rather than between-subject differences in mood state. As a further caveat, the sample size is fairly small, and so these data should be considered preliminary until they are replicated in a larger sample of subjects. In fact, the reduced statistical power associated with this sample size may underlie the lack of an interaction between MIP and time on the state ratings on the first visit. Nevertheless, the fact that the findings support a previously proposed hypothesis is promising.

\section{Conclusion}

In summary, these data provide preliminary support for the associative hypothesis of recurrence in depression. Reduced serotonin can evoke negative mood in healthy individuals but only in those who have previously experienced concurrent negative mood and reduced serotonin. It is hypothesised that this is because Hebbian associations form between the neural substrates of mood and 5-HT during their co-occurrence. As both reduced serotonin and negative mood are seen in depression, this may also explain why serotonin reduction can reliably induce negative mood in subjects who have recovered from depression but has no effect upon the moods of healthy individuals. These associations may therefore underlie, at least in part, the kindling effect in which an episode of depression makes subsequent episodes increasingly likely. As depression is a costly and growing problem, future research should therefore examine the neural basis of, and the possibility of breaking, these putative associations, thereby reducing recurrence in depression. The next step, however, is to replicate these preliminary findings in a larger sample of subjects.

Acknowledgements This work was conducted within the Behavioural and Clinical Neuroscience Institute, which is co-funded by the Medical Research Council and the Wellcome Trust. The research was funded by a programme grant from The Wellcome Trust (grant number 076274/Z04/Z to TW Robbins, BJ Everitt, AC Roberts and BJ Sahakian). We are grateful to Stuart Fuller and the staff of the Wellcome Trust Clinical Research Facility, Addenbrooke's Hospital, Cambridge. We thank Mike Franklin for analysis of plasma data. OJR holds an MRC Research Studentship.

Open Access This article is distributed under the terms of the Creative Commons Attribution Noncommercial License which permits any noncommercial use, distribution, and reproduction in any medium, provided the original author(s) and source are credited.

\section{References}

APA (2000) Diagnostic and statistical manual of mental disorders: DSM-IV. American Psychiatric Association, Arlington

Ardis TC, Cahir M, Elliott JJ, Bell R, Reynolds GP, Cooper SJ (2009) Effect of acute tryptophan depletion on noradrenaline and dopamine in the rat brain. J Psychopharmacol 23:51-55

Beddington J, Cooper CL, Field J, Goswami U, Huppert FA, Jenkins R, Jones HS, Kirkwood TBL, Sahakian BJ, Thomas SM (2008) The mental wealth of nations. Nature 455:1057-1060

Booij L, Van der Does W, Benkelfat C, Bremner D, Cowen PJ, Fava M, Gillin C, Leyton M, Moore P, Smith KA, Van der Kloot WA (2002) Predictors of mood response to acute tryptophan depletion: a reanalysis. Neuropsychopharmacology 27:852-861

Booij L, Van der Does AJW, Riedel WJ (2003) Monoamine depletion in psychiatric and healthy populations: review. Mol Psychiatry 8:951-973

Bouhuys AL, Sam MM (2000) Lack of coordination of nonverbal behaviour between patients and interviewers as a potential risk factor to depression recurrence: vulnerability accumulation in depression. J Affect Disord 57:189-200

Bouton ME (2002) Context, ambiguity, and unlearning: sources of relapse after behavioral extinction. Biol Psychiatry 52:976-986

Carpenter LL, Anderson GM, Pelton GH, Gudin JA, Kirwin PD, Price LH, Heninger GR, McDougle CJ (1998) Tryptophan depletion during continuous CSF sampling in healthy human subjects. Neuropsychopharmacology 19:26-35

Caspi A, Sugden K, Moffitt TE, Taylor A, Craig IW, Harrington H, McClay J, Mill J, Martin J, Braithwaite A, Poulton R (2003) Influence of life stress on depression: moderation by a polymorphism in the 5-HTT gene. Science 301:386-389

Cools R, Calder A, Lawrence A, Clark L, Bullmore E, Robbins T (2005) Individual differences in threat sensitivity predict serotonergic modulation of amygdala response to fearful faces. Psychopharmacology 180:670-679

Cools R, Sheridan M, Jacobs E, D'Esposito M (2007) Impulsive personality predicts dopamine-dependent changes in frontostriatal activity during component processes of working memory. J Neurosci 27:5506-5514

Cools R, Robinson OJ, Sahakian B (2008) Acute tryptophan depletion in healthy volunteers enhances punishment prediction but does not affect reward prediction. Neuropsychopharmacology 33:2291-2299

Cowen PJ, Parry-Billings M, Newsholme EA (1989) Decreased plasma tryptophan levels in major depression. J Affect Disord 16:27-31

Damasio A (2000) The feeling of what happens, 1st edn. Random House, London

Delgado PL, Charney DS, Price LH, Aghajanian GK, Landis H, Heninger GR (1990) Serotonin function and the mechanism of antidepressant action. Reversal of antidepressant-induced remission by rapid depletion of plasma tryptophan. Arch Gen Psychiatry 47:411-418

Dickinson A (1981) Conditioning and associative learning. Br Med Bull 37:165-168 
Drevets WC, Frank E, Price JC, Kupfer DJ, Holt D, Greer PJ, Huang Y, Gautier C, Mathis C (1999) Pet imaging of serotonin 1A receptor binding in depression. Biol Psychiatry 46:1375-1387

Ellenbogen MA, Young SN, Dean P, Palmour RM, Benkelfat C (1996) Mood response to acute tryptophan depletion in healthy volunteers: sex differences and temporal stability. Neuropsychopharmacology 15:465-474

Ellis PM, Salmond C (1994) Is platelet imipramine binding reduced in depression? A meta-analysis. Biol Psychiatry 36:292-299

Evers EAT, van der Veen FM, Jolles J, Deutz NEP, Schmitt JAJ (2006) Acute tryptophan depletion improves performance and modulates the BOLD response during a Stroop task in healthy females. NeuroImage 32:248-255

Fossati P, Harvey P-O, Le Bastard G, Ergis A-M, Jouvent R, Allilaire J-F (2004) Verbal memory performance of patients with a first depressive episode and patients with unipolar and bipolar recurrent depression. J Psychiatr Res 38:137-144

Garrett AS, Maddock RJ (2006) Separating subjective emotion from the perception of emotion-inducing stimuli: an fMRI study. NeuroImage 33:263-274

Gray JR, Braver TS, Raichle ME (2002) Integration of emotion and cognition in the lateral prefrontal cortex. Proc Natl Acad Sci USA 99:4115-4120

Habel U, Klein M, Kellermann T, Shah NJ, Schneider F (2005) Same or different? Neural correlates of happy and sad mood in healthy males. Neuroimage 26:206-214

Harmer CJ (2008) Serotonin and emotional processing: does it help explain antidepressant drug action? Neuropharmacology 55:1023-1028. doi:10.1016/j.neuropharm.2008.06.036

Heils A, Teufel A, Petri S, Stober G, Riederer P, Bengel D, Lesch KP (1996) Allelic variation of human serotonin transporter gene expression. J Neurochem 66:2621

Kendler KS, Kuhn J, Prescott CA (2004) The interrelationship of neuroticism, sex, and stressful life events in the prediction of episodes of major depression. Am J Psychiatry 161:631-636

Kendler KS, Thornton LM, Gardner CO (2001) Genetic risk, number of previous depressive episodes, and stressful life events in predicting onset of major depression. Am J Psychiatry 158:582-586

Kessing LV, Hansen MG, Andersen PK, Angst J (2004) The predictive effect of episodes on the risk of recurrence in depressive and bipolar disorders - a life-long perspective. Acta Psychiatr Scand 109:339-344

Lacasse JR, Leo J (2005) Serotonin and depression: a disconnect between the advertisements and the scientific literature. PLoS Med 2:e392

Lesch KP, Bengel D, Heils A, Sabol SZ, Greenberg BD, Petri S, Benjamin J, Muller CR, Hamer DH, Murphy DL (1996) Association of anxiety-related traits with a polymorphism in the serotonin transporter gene regulatory region. Science 274:1527

Lewinsohn PM, Allen NB, Seeley JR, Gotlib IH (1999) First onset versus recurrence of depression: differential processes of psychosocial risk. J Abnorm Psychol 108:483-489

Mayberg HS, Liotti M, Brannan SK, McGinnis S, Mahurin RK, Jerabek PA, Silva JA, Tekell JL, Martin CC, Lancaster JL, Fox PT (1999) Reciprocal limbic-cortical function and negative mood: converging PET findings in depression and normal sadness. Am J Psychiatry 156:675-682

Mitchell RLC, Phillips LH (2007) The psychological, neurochemical and functional neuroanatomical mediators of the effects of positive and negative mood on executive functions. Neuropsychologia 45:617-629

Mueller TI, Leon AC, Keller MB, Solomon DA, Endicott J, Coryell W, Warshaw M, Maser JD (1999) Recurrence after recovery from major depressive disorder during 15 years of observational followup. Am J Psychiatry 156:1000-1006
Murray C, Lopez A (1996) The global burden of disease: a comprehensive assessment of mortality and disability from diseases, injuries and risk factors in 1990 and projected to 2020. Harvard University Press, Cambridge

Murphy FC, Smith KA, Cowen PJ, Robbins TW, Sahakian BJ (2002) The effects of tryptophan depletion on cognitive and affective processing in healthy volunteers. Psychopharmacology 163:42-53

Nandrino J-L, Pezard L, Poste A, Reveillere C, Beaune D (2002) Autobiographical memory in major depression: a comparison between first-episode and recurrent patients. Psychopathology $35: 335-340$

Nandrino J-L, Dodin V, Martin P, Henniaux M (2004) Emotional information processing in first and recurrent major depressive episodes. J Psychiatr Res 38:475-484

Neumeister A, Konstantinidis A, Stastny J, Schwarz MJ, Vitouch O, Willeit M, Praschak-Rieder N, Zach J, de Zwaan M, Bondy B, Ackenheil M, Kasper S (2002) Association between serotonin transporter gene promoter polymorphism (5HTTLPR) and behavioral responses to tryptophan depletion in healthy women with and without family history of depression. Arch Gen Psychiatry 59:613-620

Orne MT (1969) Demand characteristics and the concept of quasicontrols. In: Rosenthal R, Rosnow R (eds) Artifact in behavioral research. Academic, New York, pp 143-179

Owens MJ, Nemeroff CB (1994) Role of serotonin in the pathophysiology of depression: focus on the serotonin transporter. Clin Chem 40:288-295

Paradiso S, Lamberty GJ, Garvey MJ, Robinson RG (1997) Cognitive impairment in the euthymic phase of chronic unipolar depression. J Nerv Ment Dis 185:748

Paulsen O, Sejnowski TJ (2000) Natural patterns of activity and longterm synaptic plasticity. Curr Opin Neurobiol 10:172-180

Placidi GPA, Oquendo MA, Malone KM, Huang Y-Y, Ellis SP, Mann JJ (2001) Aggressivity, suicide attempts, and depression: relationship to cerebrospinal fluid monoamine metabolite levels. Biol Psychiatry 50:783-791

Post RM, Weiss SR (1998) Sensitization and kindling phenomena in mood, anxiety, and obsessive-compulsive disorders: the role of serotonergic mechanisms in illness progression. Biol Psychiatry 44:193-206

Reilly JG, McTavish SFB, Young AH (1997) Rapid depletion of plasma tryptophan: a review of studies and experimental methodology. J Psychopharmacol 11:381-392

Robinson O (2009) Serotonin and mood state influences on cognition: implications for depression department of psychiatry. University of Cambridge, Cambridge

Robinson OJ, Sahakian BJ (2008a) P.2.30 Triple dissociation of serotonergic influence on motivational behaviour under positive, negative and neutral mood. Eur Neuropsychopharmacol 18: s60-s61

Robinson OJ, Sahakian BJ (2008b) Recurrence in major depressive disorder: a neurocognitive perspective. Psychol Med 38: 315-318

Robinson OJ, Sahakian BJ (2009) A double dissociation in the roles of serotonin and mood in healthy subjects. Biol Psychiatry 65:89-92

Robinson OJ, Cools R, Crockett M, Sahakian BJ (2009) Mood state moderates the role of serotonin in cognitive biases. J Psychopharmacol. doi:10.1177/0269881108100257

Roiser JP, Blackwell AD, Cools R, Clark L, Rubinsztein DC, Robbins TW, Sahakian BJ (2006) Serotonin transporter polymorphism mediates vulnerability to loss of incentive motivation following acute tryptophan depletion. Neuropsychopharmacology 31:2264 2272

Roiser JP, Levy J, Fromm SJ, Wang H, Hasler G, Sahakian BJ, Drevets WC (2007) The effect of acute tryptophan depletion on 
the neural correlates of emotional processing in healthy volunteers. Neuropsychopharmacology 33:1992-2006

Roiser J, Farmer A, Lam D, Burke A, O'Neill N, Keating S, Smith GP, Sahakian B, McGuffin P (2008) The effect of positive mood induction on emotional processing in euthymic individuals with bipolar disorder and controls. Psychological Medicine 1-7. doi: $10.1017 / \mathrm{S} 0033291708004200$

Ruhe HG, Mason NS, Schene AH (2007) Mood is indirectly related to serotonin, norepinephrine and dopamine levels in humans: a meta-analysis of monoamine depletion studies. Molecular Psychiatry 12:331-359

Sambeth A, Blokland A, Harmer CJ, Kilkens TOC, Nathan PJ, Porter RJ, Schmitt JAJ, Scholtissen B, Sobczak S, Young AH, Riedel WJ (2007) Sex differences in the effect of acute tryptophan depletion on declarative episodic memory: a pooled analysis of nine studies. Neurosci Biobehav Rev 31:516-529

Segal ZV, Williams JM, Teasdale JD, Gemar M (1996) A cognitive science perspective on kindling and episode sensitization in recurrent affective disorder. Psychol Med 26:371-380

Sher L, Oquendo MA, Galfalvy HC, Cooper TB, Mann JJ (2004) The number of previous depressive episodes is positively associated with cortisol response to fenfluramine administration. Ann N Y Acad Sci 1032:283-286
Smith KA, Fairburn CG, Cowen PJ (1997) Relapse of depression after rapid depletion of tryptophan. Lancet 349:915-919

Taylor Tavares JV, Clark L, Furey ML, Williams GB, Sahakian BJ, Drevets WC (2008) Neural basis of abnormal response to negative feedback in unmedicated mood disorders. NeuroImage 42:1118-1126

Thase ME, Kupfer DJ, Buysse DJ, Frank E, Simons AD, McEachran AB, Rashid KF, Grochocinski VJ (1995) Electroencephalographic sleep profiles in single-episode and recurrent unipolar forms of major depression: I. Comparison during acute depressive states. Biol Psychiatry 38:506-515

Van der Does AJ (2001) The effects of tryptophan depletion on mood and psychiatric symptoms. J Affect Disord 64:107-119

van der Veen FM, Evers EAT, Deutz NEP, Schmitt JAJ (2007) Effects of acute tryptophan depletion on mood and facial emotion perception related brain activation and performance in healthy women with and without a family history of depression. Neuropsychopharmacology 32:216-224

Young SN, Smith SE, Pihl RO, Ervin FR (1985) Tryptophan depletion causes a rapid lowering of mood in normal males. Psychopharmacology 87:173-177

Young SN, Smith S, Pihl RO, Ervin FR (1986) Tryptophan depletion lowers mood in normal males. Int J Neurosci 31:219-219 